\title{
Role of Speech in Orthognathic Surgery: A Review
}

Dr. Rahul Vinay Chandra Tiwari, FOGS, MDS ${ }^{1 *}$, Dr. Mandarapu Satya Karthik, MDS $^{2}$, Dr. Krishna Sai Prasad, MDS ${ }^{3}$, Dr. Jacob John Plackal ${ }^{4}$, Dr. Vedatrayi, MDS ${ }^{5}$, Dr. Sushil Bhagwan Mahajan ${ }^{6}$, Dr. Heena Tiwari, BDS, PGDHHM ${ }^{7}$

${ }^{1}$ Assistant Professor, Department of Oral and Maxillofacial Surgery, Sri Sai College of Dental Surgery, Vikarabad, India

${ }^{2}$ Oral And Maxillofacial Surgeon, Sr lecturer, Drs Sudha \& Nageswara Rao Siddhartha Institute of Dental Sciences, Chinaoutpalli, Gannavaram Mandal, Krishna District, Andhra Pradesh, India

${ }^{3}$ Consultant Oral and maxillofacial surgeon, Happy Smile Dental Care, Himayatnagar,Hyderabad Telangana State, India

${ }^{4}$ Consultant Oral and Maxillofacial surgeon, Believers Church Medical Centre, Konni, Pathanamthitta, Kerala, India

${ }^{5}$ Consultant oral and maxillofacial surgeon, Tnagar Chennai, India

${ }^{6}$ 2nd Yr Mds Orthodontics and Dentofacial Orthopedic, Dr. H.S.R.S.M. Dental College and Hospital Hingoli, Maharashtra, India

${ }^{7}$ Government Dental Surgeon, Chhattisgarh, India

DOI:10.36348/SJMPS.2019.v05i09.001

| Received: 15.08.2019 | Accepted: 01.09.2019| Published: 15.09.2019

*Corresponding author: Dr. Rahul Vinay Chandra Tiwari

\section{Abstract}

Literature has shown that severe dental and skeletal malocclusions can have varying detrimental effects on speech production. This is due to the impairment of the orofacial structures which play a key role in the production of speech. Orthognathic surgery which aims to restore the balance between the dentofacial structures by correcting the dentofacial deformities is believed to have a positive effect on the speech production in such patients. This review throws light on the role of speech in patients undergoing orthognathic surgery.

Keywords: Speech, Orthognathic Surgery.

Copyright @ 2019: This is an open-access article distributed under the terms of the Creative Commons Attribution license which permits unrestricted use, distribution, and reproduction in any medium for non-commercial use (NonCommercial, or CC-BY-NC) provided the original author and source are credited.

\section{INTRODUCTION}

The orofacial structures play a vital role in the speech outcome. When the orofacial structures are affected, there are particular sounds that are more susceptible to production errors than others [1]. These kind of clinical scenarios are particularly encountered in patients with cleft lip \& palate. Even though there are numerous clinical studies demonstrating the significance of orthognathic surgery for the correction of maxillomandibular discrepancies, the functional outcomes of these procedures on speech in patients with cleft lip and palate have not been fully documented.

Orthognathic surgery in patients with dentofacial deformity will have beneficial effects on the function as well as the esthetics of an individual. In addition to this, it can improve the articulation of certain sounds by adjusting the positioning of lips and teeth. The purpose of this article is to highlight the types of speech errors that are often seen in individuals who have dentofacial skeletal deformities, and to discuss the impact of conventional orthognathic surgery on speech production.

\section{Errors in Patients with Class II Malocclusion}

Individuals who have severe Class II malocclusion often have difficulty producing bilabial consonants such as $/ \mathrm{p} /, \mathrm{b} /$, and $/ \mathrm{m} /$. The production of these sounds requires the upper and lower lips to contact each other. However, in patients with Class II malocclusion, the lower lip comes in contact with the upper anterior teeth. There is also distortion of sounds like /s/, /z/, /f /, and /3 /.This is due to the presence of deep bite [2].

\section{Articulation errors in patients with Class III malocclusion}

Class III malocclusion also tends to have difficulty with the lingua-alveolar consonants /t/, /d/, /l/, $/ \mathrm{n} /, \mathrm{s} /$, and $/ \mathrm{z} /$. These sounds should be produced with tongue-tip approximating the alveolar ridge. Instead, individuals who have Class III malocclusion often produce this sound with the tip of the tongue contacting the maxillary incisors [2].

\section{Articulation errors in patients with crossbites}

Patients with unilateral / bilateral cross-bites exhibit errors in sounds like /s/, /z/, /f/, /3/, /t/, and / $\mathrm{d}_{3} /$. This is because the sounds are often laterally released from the oral cavity by the lowering of one or both sides of the tongue. 
The impact of maxillary distraction osteogenesis on speech and resonance has been investigated by Guyette and colleagues [7]. They observed that most of the patients who presented with hyponasality preoperatively showed a reduction in hyponasality, resulting in improved speech. They concluded that the risk of velopharyngeal dysfunction in individuals who had clefts and who underwent maxillary distraction osteogenesis was similar to outcomes following Le Fort I maxillary advancement [7].

\section{Role of Orthognathic Surgery on Speech Production}

It is a proven fact that orofacial structures play a vital role in the speech outcome. Impairment in the function of the orofacial structures lead to errors in the production of sounds leading to speech disturbances. Orthognathic surgery has the potential to improve speech errors relating to the malocclusion, as the relationship between the lips and teeth are normalized [1].

However, there exists a controversy pertaining to the role of orthognathic surgery pertaining to correction of speech disturbances. Dalston and Vig reported that in 40 patients who underwent either maxillary or mandibular orthognathic surgery, only two subjects demonstrated deterioration in speech, one made improvements, and the remaining subjects had no noticeable change in speech production [3].

Ruscello and colleagues reported findings from a group of 20 patients who also underwent mandibular or maxillary orthognathic procedures. They noted that most patients who demonstrated speech errors preoperatively exhibited improvements in their speech, whereas none exhibited deteriorations in speech production [4]. A recent study showed that when only patients who did not have a history of clefting and who underwent maxillary distraction were included in a sample, improvements in articulation were noted immediately following the procedure and at 1 year postoperatively for most patients [5].

Following Le Fort I osteotomy, few studies reported essentially no change based on perceptual and nasendoscopy studies [6]. However, few studies found velopharyngeal area and nasalance scores to increase [1]. The basic observation that increase in velopharyngeal areas and nasalance scores is of clinical importance because those individuals who have smaller velopharyngeal areas and decreased nasalance scores may have improved resonance following advancement. Those individuals who already have high velopharyngeal areas and nasalance scores preoperatively may demonstrate deteriorations in resonance as an excessive level of acoustic energy enters the nasal cavity [2].

It can be postulated that the slow movement of the maxilla in distraction allows the patient to be able to adapt to the changes over time, with increased muscular activity of velopharyngeal closure. In addition to this, in maxillary distraction, the process can be stopped at any point that undesirable speech characteristics are judged to begin to emerge. This added advantage is unlikely in traditional orthognathic surgery, which accomplishes an immediate surgical rearrangement of maxillofacial structures, and does not afford the same type of ongoing assessment of speech outcome afforded by gradual maxillary distraction.

Pertaining to the impact of mandibular distraction on speech and nasal resonance, patients who do not have a history of speech or hearing disorders have not been shown to have long-term effects following bilateral sagittal split ramus osteotomy on acoustic measures of vowel quality [8]. Patients who have a history of hemifacial microsomia and who undergo mandibular distraction osteogenesis may present with immediate declines in articulation and velopharyngeal function following distraction, but performance typically returns to preoperative levels when followed over time [9]. Mandibular distraction appears to have a limited impact on speech and resonance [2].

A study conducted on 34 patients who underwent orthognathic surgery claims that orthognathic surgery used to correct occlusal defects leads to improvement in articulation in most cases [11]. Even though subjects from the closed-bite and openbite group demonstrated improvement in articulation after surgery, the pattern of articulatory changes were different in both the two groups. Improvement in the closed-bite group was greater at 3 months than in the open-bite group, but reached a plateau thereafter. In contrast, the reduction in the mean number of errors in the open-bite group was minimal at 3 months, but continued to decline over time. By 12 months, the openbite group had fewer errors than the closed-bite group, as was the case before surgery [10].

It is noted that the improvement in articulation in most of the subjects was spontaneous, without the benefit of speech therapy in the interim, seems to 
support the supposition that the tongue can easily make adjustments within the new oral environment. It also suggests that if a person eliminates errors, it is unlikely that these errors will recur. In those patients who retained speech errors, possible dental/skeletal relapse may have occurred. If such a condition existed, the individual would likely find it difficult to produce a correct sound, particularly the sibilant, because the oral environment would not be conducive to permitting the narrow anterior airstream necessary for its correct production.

A recent study evaluated how advancement of the maxilla would affect the speech and articulation disorders in patients with cleft lip and palate. The result of the study confirms previous findings that patients with clefts of the lip and palate or palate alone are predisposed to velopharyngeal function alteration after maxillary advancement, particularly with borderline function preoperatively. However, the results show that surgical correction of skeletal relationships and occlusion may translate into improvements in certain aspects of speech disorders [11].

\section{CONCLUSION}

Individuals undergoing conventional maxillary advancement surgery or maxillary distraction should be afforded perceptual and instrumental assessment of speech and velopharyngeal function, both preoperatively and postoperatively. Counseling should be provided that there could be some risk of deterioration in velopharyngeal function for speech, particularly for those individuals who have repaired cleft palate already presenting with characteristics of borderline velopharyngeal function. On the other hand, the same individuals should be counseled that there may be a positive change in speech articulation, with normalization of the maxillary-mandibular relationship. It can be concluded that orthognathic surgery has the potential to improve speech errors relating to the malocclusion, as the relationship between the lips and teeth are normalized.

\section{REFERENCES}

1. Trindade, I. E., Yamashita, R. P., Suguimoto, R. M., Mazzottini, R., \& Trindade Jr, A. S. (2003). Effects of orthognathic surgery on speech and breathing of subjects with cleft lip and palate: acoustic and aerodynamic assessment. The Cleft palate-craniofacial journal, 40(1), 54-64.
2. O'Gara, M., \& Wilson, K. (2007). The effects of maxillofacial surgery on speech and velopharyngeal function. Clinics in plastic surgery, 34(3), 395-402.

3. Dalston, R. M., \& Vig, P. S. (1984). Effects of orthognathic surgery on speech: a prospective study. American journal of orthodontics, 86(4), 291-298.

4. Ruscello, D. M., Tekieli, M. E., Jakomis, T., Cook, L., \& Van Sickels, J. E. (1986). The effects of orthognathic surgery on speech production. American journal of orthodontics, 89(3), 237-241.

5. Lee, A. S., Whitehill, T. L., Ciocca, V., \& Samman, N. (2002). Acoustic and perceptual analysis of the sibilant sound/s/before and after orthognathic surgery. Journal of Oral and Maxillofacial surgery, 60(4), 364-372.

6. Sell, D., Ma, L., James, D., Mars, M., \& Sheriff, M. (2002). A pilot study of the effects of transpalatal maxillary advancement on velopharyngeal closure in cleft palate patients. Journal of Cranio-Maxillofacial Surgery, 30(6), 349-354.

7. Guyette, T. W., Polley, J. W., Figueroa, A., \& Smith, B. E. (2001). Changes in speech following maxillary distraction osteogenesis. The Cleft palate-craniofacial journal, 38(3), 199-205.

8. Niemi, M., Laaksonen, J. P., Peltomäki, T., Kurimo, J., Aaltonen, O., \& Happonen, R. P. (2006). Acoustic comparison of vowel sounds produced before and after orthognathic surgery for mandibular advancement. Journal of oral and maxillofacial surgery, 64(6), 910-916.

9. Guyette, T. W., Polley, J. W., Figueroa, A. A., \& Cohen, M. N. (1996). Mandibular distraction osteogenesis: effects on articulation and velopharyngeal function. The Journal of craniofacial surgery, 7(3), 186-191.

10. Valling, L. D. (1990). Speech, velopharyngeal function, and hearing before and after orthognathic surgery. Journal of oral and maxillofacial surgery, 48(12), 1274-1281.

11. Janulewicz, J., Costello, B. J., Buckley, M. J., Ford, M. D., Close, J., \& Gassner, R. (2004). The effects of Le Fort I osteotomies on velopharyngeal and speech functions in cleft patients. Journal of Oral and Maxillofacial Surgery, 62(3), 308-314. 